\title{
EDITORIAL
}

\section{Public trust in science: Climate, energy and public health}

The last year and a half has been extraordinary in all aspects of our lives. We went through a few lockdowns and all large gatherings such as our MRS annual meetings became virtual online events only. At this time, many MRS members are hoping that at least some of us will meet in person in December in Boston for the Fall MRS meeting. Fingers crossed.

The silver lining for me as a scientist is that I do have more time for thinking and planning-one of the best things to do during the isolation periods. For MRS Energy and Sustainability, it is the perfect time to expand our editorial board as we are seeing unprecedented public support for expanding research in energy technologies to fight the climate crisis. In fact, in the era of COVID, more than ever people realize that we must handle the climate crisis with more proactive actions. The lessons we learned from the pandemic taught us that global collaborations are needed to resolve global scale crisis! As our journal is the MRS journal for energy materials research that showcases the convergent research among science, technology, economics and policy, we are honored to introduce five new board members from different continents with diverse expertise to join our prestigious editorial advisory board https://www.springer.com/ journal/43581/updates/18623170.

Prof. Koji Amezawa, Tohoku University, Japan

Prof. Sossina M. Haile, Northwestern University, USA

Prof. Pooi See Lee, Nanyang Technological University, Singapore

Prof. Aron Walsh, Imperial College London, UK

Prof. Karen Winey, University of Pennsylvania, USA

Let's recall the idea of the Materials Research Society, which took flight in the rich milieu of scientific research during the post-World War II era. MRS was officially established in 1973, arisen from the tremendous technical accomplishments of US science and technology during the war. For nearly half a century, MRS has been fulfilling the mission as "an organization of materials researchers worldwide that promotes communication for the advancement of interdisciplinary materials research and technology to improve the quality of life." Professional societies like MRS take a leadership role in dissemination of information on materials science and technology to the public and to governments. Scientific research is a torturous journey filled with obstacles and missteps, but providing archival literature in the field of materials research and technology is a key historical task of scientific institutions. A scientist like myself should always hold herself to the highest standards when recording, analyzing and reporting data. Communication to the public must be done with the highest quality information and at suitable forums, where we can prevent misinformation and miscommunications.

The public trust in Science, in the era of public health and climate crises, must be treasured and raised. We, the scientists, should consider this as our responsibility and our mission to fulfill.

\section{Y. Shirley Meng} Editor-in-Chief

\section{Open Access}

This article is licensed under a Creative Commons Attribution 4.0 International License, which permits use, sharing, adaptation, distribution and reproduction in any medium or format, as long as you give appropriate credit to the original author(s) and the source, provide a link to the Creative Commons licence, and indicate if changes were made. The images or other third party material in this article are included in the article's Creative Commons licence, unless indicated otherwise in a credit line to the material. If material is not included in the article's Creative Commons licence and your intended use is not permitted by statutory regulation or exceeds the permitted use, you will need to obtain permission directly from the copyright holder. To view a copy of this licence, visit http://creativecommons. org/licenses/by/4.0/. 